\title{
PERAN KONTRIBUTOR BERITA DAN JURNALISME WARGA SECARA INDUSTRIAL DALAM ERA MASYARAKAT INFORMASI
}

\author{
Restiawan Permana \\ Prodi IImu Komunikasi Fakultas IImu Sosial dan IImu Politik \\ Universitas Satya Negara Indonesia \\ restiawan.pmn@gmail.com
}

\begin{abstract}
Abstrak
Pertumbuhan praktek jurnalistik saat ini menjadi tren tersendiri bagi industri media massa. Media massa telah memberdayakan masyarakat dalam membuat informasi dan sekaligus menjadikan mereka sebagai produsen berita. Salah satu praktek jurnalistik ini disebut dengan istilah jurnalisme warga (citizen journalism). Meskipun jurnalisme warga secara istilah memang baru dikenal baru-baru ini, akan tetapi secara konsep praktik jurnalisme warga ini sudah ada sejak manusia mengenal tulisan dan mengenal media sebagai saluran komunikasi massa. Citizen journalism menjadi penting karena bisa menjadi pelengkap bagi "lubanglubang" berita yang tidak terendus oleh para wartawan profesional. Semakin terlihat jelas persaingan antara wartawan profesional dengan khalayak pembuat berita (citizen journalism) dalam kedudukannya sebagai insan media. Nyatanya, saat ini semakin banyak perusahaan media yang mempekerjakan jurnalis yang berstatus kontributor namun jaminan hidup bagi mereka tidak jelas. Perusahaan media kerap memanfaatkan ketidakjelasan status ini, untuk mengingkari hak-hak pekerja yang diatur dalam undang-undang ketenagakerjaan, enggan memberikan upah yang layak, enggan memberikan jaminan kesehatan serta tunjangan lainnya yang bisa membuat jurnalis kontributor bekerja lebih profesional. Di sisi lain, honor citizen journalism di Indonesia justru cukup menggiurkan.
\end{abstract}

Kata kunci: peran kontributor, jurnalisme warga, masyarakat informasi

\begin{abstract}
The current level of journalism education is becoming a trend for the mass media industry. Mass media has empowered the public in making information and at the same time making them as news producers. One of these journalistic practices is called by citizen journalism. Although citizen journalism is newly known recently, but in general there are many media that are used as a media of communication. Citizen journalism is important because it can be a complement to the "holes" of news unfocused by professional journalists. More clearly visible between journalists and newsmakers (citizen journalism) in his position as a media person. In fact, today more and more media companies are contributor status and are still alive for them is not clear. Media companies often exploit the uncertainty of this status, to deny workers' rights set out in labor law, to be reluctant to provide decent wages, to be reluctant to provide health and other benefits that can make contributing journalists work more professionally. On the other hand, honor citizen journalism in Indonesia is quite tolerable.
\end{abstract}

Keywords: role of contributors, citizen journalism, information society 


\section{Pendahuluan}

Berbicara soal berita, tidak selalu identik sebagai "produk" yang dibuat oleh seorang wartawan atau jurnalis. Kenyataannya, saat ini berita atau informasi dibuat oleh masyarakat yang awam tentang pengetahuan jurnalistik. Kondisi tersebut memunculkan suatu aktivitas jurnalistik semu di kalangan masyarakat di era masyarakat informasi. Menurut Rogers (dalam Zulkarimein, 2008:6) masyarakat informasi dirumuskan sebagai suatu bangsa di mana mayoritas angakatan kerja adalah terdiri dari para pekerja informasi dan dimana informasi merupakan elemen yang paling penting. Jadi masyarakat informasi mencerminkan suatu perubahan yang tajam dari masyarakat industrial dimana mayoritas tenaga kerja bekerja dalam pekerjaan manufacturing seperti perakitan mobil dan produksi baja, dimana eleman kunci adalah energi. Kontras dengan itu, para pekerja individu pada masyarakat individu pada masyarakat informasi adalah mereka yang aktivitas utamanya memproduksi, mengolah atau mendistribusikan informasi, dan memproduksi teknologi informasi.

Era informasi ini menyebabkan tingginya rasa ingin tahu masyarakat terhadap suatu hal. Ditambah lagi karena mudahnya dalam mengelola informasi (mulai dari mencari sampai mendistribusikan), maka menghasilkan tren baru dalam memproduksi berita. Masyarakat tidak hanya pasif dalam menerima informasi dari media massa seperti dulu. Teori Peluru atau Teori Jarum Suntik/Hipodermik relevan untuk menggambarkan kondisi masyarakat pada saat itu.

Teori Jarum Hipodermik ini meyakinkan bahwa kegiatan mengirimkan pesan sama halnya dengan tindakkan menyuntikkan obat yang bisa langsung masuk kedalam jiwa penerima pesan. Sebagaimana peluru yang ditembakkan dan langsung masuk kedalam tubuh (Morissan, 2013:504). Media menyajikan stimuli perkasa yang secara seragam diperhatikan oleh massa. Stimuli yang membangkitkan desakan, emosi, atau proses lain yang hampir tidak terkontrol oleh individu. Setiap anggota massa memberikan respons yang sama pada stimuli yang datang dari media massa. Teori ini mengasumsikan massa yang tidak berdaya ditembaki oleh stimuli media massa maka disebut dengan "teori peluru" (bullet theory) atau "model hipodermik" yang menganalogikan pesan komunikasi seperti obat yang disuntikkan dengan jarum ke bawah kulit pasien (DeFleur dalam Rakhmat, 2008:197).

Setelah semakin berkembangnya media massa (konvensional) hingga melahirkan media baru (internet), lama-kelamaan Teori Peluru dianggap kurang relevan lagi. Tentunya, hal ini berdampak pada industri media massa dalam memproduksi berita. Salah satu praktek jurnalistik yang sering digunakan oleh institusi media massa saat ini adalah Citizen Journalism. Menurut Shayne Bowman dan Chris Willis (2003:48), citizen journalism memiliki arti "tindakan warga sipil, atau sekelompok warga sipil, yang memainkan peran yang aktif dalam proses pengumpulan, pelaporan, analisa serta penyebaran berita dan informasi." Tindakan yang dilakukan oleh warga sipil dalam memproduksi berita ini tentunya berbeda dengan jurnalisme mainstream. 
Perkembangan citizen journalism menggembirakan karena memungkinkan masyarakat memiliki akses untuk menjadi subyek dalam pemberitaan. Masyarakat juga mendapat kesempatan menyuarakan aspirasinya karena memiliki ruang di media massa. Hal ini penting mengingat media massa - meski berada di dalam lingkup negara yang memiliki kebebasan pers - tetap memiliki keterbatasan misalnya kecondongan pada berbagai kepentingan terutama kapital dan politis. Dengan demikian, maka penting untuk menyambut citizen journalism yang diharapkan akan memberikan warna tersendiri yang lebih independen dan jujur di dunia media khususnya di Indonesia.

Dalam praktek citizen journalism, biasanya perusahaan-perusahaan media massa memberikan kesempatan bagi masyarakat untuk memberikan timbal balik. Pemberian konteks cerita melalui rujukan berita (hyperlinks) juga menjadi poin penting. Di sisi lain, media massa diuntungkan karena tidak perlu merekrut banyak orang untuk menjadi jurnalis. Citizen journalism berada sama posisi dengan jurnalis profesional termasuk tugasnya yaitu meliput, menganalisa dan menyiarkan berita yang dibuatnya. Media massa cukup menerima berita dari citizen journalism.

Pertumbuhan praktek jurnalistik ini menjadi tren tersendiri bagi industri media massa. Media massa telah memberdayakan masyarakat dalam membuat informasi dan sekaligus menjadikan mereka sebagai produsen berita. Semakin terlihat jelas persaingan antara wartawan profesional dengan masyarakat pembuat berita (citizen journalism) dalam kedudukannya sebagai insan media. Pendapat penulis melihat fenomena tersebut yang pertama adalah saat ini kita berada pada era masyarakat informasi di mana masyarakat memiliki sikap kritis terhadap setiap peristiwa yang terjadi di sekelilingnya dan merasa peristiwa tersebut penting untuk diberitakan kepada khalayak luas, baik yang dikenal maupun tidak. Kedua, adanya pergeseran peran masyarakat (warga) yang awalnya hanya sebagai obyek berita tetapi sekarang mereka menjadi subyek berita. Ini akan berdampak pada posisi citizen journalism sebagai alternatif penyampai berita di media massa. Berdasarkan uraian-uraian tersebut, dengan ini penulis bermaksud menjelaskan secara konseptual peran wartawan, dalam hal ini koresponden atau kontributor berita serta peran citizen journalism secara industrial. Apakah keberadaan wartawan (koresponden atau kontributor) masih tetap eksis, atau citizen journalism yang akan mendominasi dalam menyampaikan informasi kepada redaksi media massa?

\section{Pembahasan}

\subsection{Sejarah Perkembangan Citizen Journalism}

Konsep pertama lahir, jurnalisme publik yang pada dasarnya dikembangkan oleh wartawan profesional untuk menyikapi meningkatnya ketidakpercayaan publik terhadap media dan kesinisan publik terhadap politik di Amerika Serikat sekitar tahun 1988. Saat itu, kritik pedas terhadap standar dan arogansi media membawa media berpikir tentang fungsi dan tanggung 
jawabnya terhadap masyarakat dan bagaimana wartawan lebih responsif dengan masalah yang menjadi perhatian masyarakat, inilah yang dikenal sebagai jurnalisme publik. Civic journalism (digunakan secara bergantian dengan jurnalisme publik) mencoba mendefinisi ulang nilai berita, mempertanyakan nilai objektivitas dan imparsialitas, mendorong keterlibatan wartawan lebih besar sebagai peserta aktif dalam masyarakat, dan menginginkan praktik jurnalisme yang mencerminkan keragaman kultural di masyarakat Amerika. Kemunculan gerakan civic journalism merupakan reaksi terhadap jurnalisme konvensional yang menghiraukan kewajiban untuk mewakili kepentingan pembacanya, dan dalam tingkat tertentu menjadi alat mengeruk keuntungan semata. Namun civic journalism yang dijalankan oleh mass media tidak mampu bertahan lama lantaran program beritanya memerlukan dana yang besar. Tahun 2003 pelopor civic journalism the Pew Center of Civic Journalism membubarkan diri. Civic journalism ini membuka pintu bagi tumbuhnya citizen journalism dimana warga yang mempunyai berita, dan foto dapat menyampaikannya langsung melalui blog atau ke beberapa mainstream media yang sudah mengakomodasi misalnya situs BBC (www.bbc.co.uk), CNN (www.cnn.com), dll. Dan dari sinilah citizen journalism lahir dan berkembang hingga saat ini.

Pada perkembangannya, kemunculan citizen journalism mendapatkan penolakan dari mainstream media yang merasa citizen jurnalis bukan profesional yang bisa melakukan reportase layaknya jurnalis profesional. Misalnya saja The New York Times yang mempertanyakan keakuratan dan objektifitas hasil peliputan citizen journalism. Traditional jurnalist juga mengaku skeptis dan menganggap citizen journalism tidak dapat melakukan peliputan dengan baik karena hanya jurnalis terlatih yang mengetahui etika media saat melakukan peliputan.

$$
\text { Jika jurnalis media massa mainstream mengerjakan sebuah }
$$

berita dengan kaidah dan standar kerja jurnalisme, maka jurnalis warga akan melaporkan berita dengan pengetahuan dan gaya mereka sendiri (http://entertainment. suaramerdeka.com/index/php/id=720). Meski mendapat kritikan pedas semacam ini, namun citizen journalism terus berkembang, bahkan pada beberapa peristiwa penting di dunia citizen journalism menjadi pihak nomor 1 yang memberikan informasi kepada masyarakat. Misalnya saja saat tsunami terbesar di Samudera Hindia, video dan informasi penting justru bersumber dari blog yang dimiliki warga. Blog-blog pribadi warga juga menjadi saksi peristiwa besar lain seperti perang Irak I, runtuhnya gedung WTC, Bom Bali I dan II, dll.

Citizen journalism adalah bentuk spesifik dari citizen media dengan content yang berasal dari publik. Di Indonesia, istilah yang dimunculkan untuk citizen journalism adalah jurnalisme partisipatoris atau jurnalisme warga (Suwandi, 2010:30). Di Indonesia sendiri, seiring dengan meningkatnya penggunaan internet di Indonesia dan tentu saja pengaruh dari tren media di era digital, citizen journalism mulai dikenal. Namun sayangnya, saat ini belum ada perhatian dan pendataan yang resmi tentang gambaran citizen journalism yang ada di Indonesia, yang pasti sebagian besar media massa baik media mainstream maupun media 
online sudah menerapkan praktek citizen journalism.

Jurnalisme warga tetaplah potensial untuk hidup di Indonesia. Jurnalisme warga terlihat semakin sering melaporkan berita dari sumber yang sebelumnya tidak terjangkau oleh wartawan profesional. Semakin media mengakomodasi publik tentunya semakin termotivasi publik untuk menyisihkan waktu untuk mengirimkan berita. Hal ini bisa terjadi karena masyarakat yang memiliki keahlian tertentu akan mempertahankan reputasinya dengan mengecek dan memverifikasi berita yang mereka buat seperti yang dilakukan wartawan profesional. Dalam situasi demikian, media tidak akan kehilangan kredibilitas malahan menaikkan citranya sebagai media publik. Kuncinya adalah menemukan warga yang memiliki keahlian tertentu untuk menjadi reporter warga bagi media (Kurniawan, 2007:75).

\subsection{Jurnalis Dilihat Dari Perspektif Sosial - Ekonomi - Politik}

Apabila dilihat dari segi finansial, seorang jurnalis memiliki penghasilan yang tidaklah besar. Beberapa bahkan digaji di bawah standar atau upah minimum. Beberapa perusahaan media massa belum dapat memberikan perlindungan dan kesejahteraan yang memadai bagi karyawannya, padahal pekerjaan sebagai jurnalis bukanlah pekerjaan yang sepele. Sedangkan dilihat dari sudut pandang sosial dan politik, aktivitas jurnalisme menstimulus persoalan baru bagi perkembangan jurnalisme itu sendiri. Pada April 2017, salah seorang jurnalis media televisi nasional dianiaya sekelompok orang pada saat meliput banjir di Kemang Jakarta Selatan. Tak puas menganiaya jurnalis tersebut, para pelaku juga merampas serta merusak properti yang mereka miliki. Kasus tersebut hanya segelintir dari banyak kasus yang menimpa para jurnalis dalam menjalankan profesinya. Hal ini menunjukkan bahwa pekerjaan sebagai jurnalis sangatlah beresiko. Maka sudah sepantasnya mereka mendapatkan kompensasi yang sepadan dengan resiko yang diambil.

Selama ini, sebagian besar masyarakat hanya mengenal istilah wartawan atau jurnalis ialah orang yang bertugas membawa informasi penting melalui saluran medianya lalu menghadirkannya di meja tamu dalam bentuk surat kabar, di ruang keluarga atau kamar tidur dalam bentuktelevisi, atau di radio dan media dalam jaringan (daring) atau online melalui telepon genggam atau gadget lainnya. Belum begitu banyak masyarakat yang memahami bahwa ada sekelompok jurnalis yang menyandang status berbeda, bukan karena keahliannya yang khusus (specialized skill), melainkan karena perbedaan perlakuan di perusahaan medianya. Di tingkat daerah, status kontributor bahkan bisa lebih buram. Banyak dari jurnalis yang bekerja tanpa status resmi, sehingga muncul istilah "tuyul" bagi jurnalis yang bekerja tanpa identitas (kartu pers). Sebagian dari mereka bekerja dengan upah alakadarnya, kualitas berita yang buruk, dan tidak mengerti kode etik. Ini belum termasuk dengan persoalan keselamatan dalam bekerja mengingat profesi jurnalis di Indonesia hingga hari ini masih rentan dengan ancaman mulai 
dari teror, intimidasi, hingga penghilangan nyawa (Fitriawan, 2014:298).

Perlu diakui untuk menjadi seorang jurnalis yang profesional memang tidak mudah, dibutuhkan beberapa keahlian baik secara teknis maupun non teknis. Seorang jurnalis juga harus memiliki mental yang kuat agar sikap profesionalismenya tetap terjaga, karena banyak pihak-pihak yang berkepentingan ingin memberdayakan mereka. Di beberapa perusahaan media massa, pekerjaan sebagai seorang jurnalis/wartawan merupakan sebuah jenjang karir yang harus dicapai atau dilewati. Misalnya, untuk menjadi editor/redaktur/pemimpin redaksi kebanyakan karir mereka dimulai dari tingkatan (level) wartawan biasa. Sedangkan status ketenagakerjaannya dimulai dari wartawan lepas, wartawan pembantu (koresponden), kemudian menjadi wartawan tetap. Dari kesemuanya, yang membedakan adalah hak dan kewajiban dari masing-masing level.

Wartawan pembantu (kontributor atau koresponden) yang belum menjadi karyawan, atau kesempatan mereka untuk menjadi karyawan memang sengaja dipersulit di perusahaan media, selayaknya tetap diberikan honor tetap yang besarannya tergantung dari perusahaan media bersangkutan atau mungkin minimal 50 persen UMK. Selebihnya mereka mendapatkan penghasilan dari honor karya jurnalistik yang dibayar berdasarkan jumlah berita yang dihasilkan dalam periode satu bulan, dan mereka tidak mendapatkan jaminan lain sebagaimana wartawan tetap. Kenyataan ini memang pahit, namun wartawan/jurnalis juga sebuah profesi yang sama dengan profesi lainnya, di mana seseorang melakukan pekerjaan tersebut untuk memenuhi kebutuhan hidupnya. Jadi apa pun perjuangannya, memilih pekerjaan ini haruslah memiliki komitmen agar menghasilkan hasil yang baik untuk perusahaannya maupun dirinya sendiri.

\subsection{Dari Kontributor/Koresponden ke Citizen Journalism}

Dalam sejumlah literatur tentang jurnalistik, pembahasan tentang koresponden hingga kini belum (tidak) mendapat tempat sama sekali, hanya ada penjelasan mengenai "wartawan" sebagai "petugas" yang "bertindak" mencari dan mengumpulkan fakta-fakta, memverifikasi akurasinya, mengajukannya kepada redaktur (Kurnia, 2005:193).

Wartawan atau reporter sebagai seseorang yang bertugas mencari, mengumpulkan, dan mengolah informasi menjadi berita, untuk disiarkan melalui media massa. Dari status pekerjaannya, Djuroto membagi wartawan menjadi tiga "kelas", yakni (1) Wartawan Tetap, yaitu wartawan yang bertugas di satu media massa (cetak atau elektronik) dan diangkat menjadi karyawan tetap di perusahaan itu. Mereka mendapat gaji tetap, tunjangan, bonus, fasilitas kesehatan, dan sebagainya serta diperlakukan sebagaimana karyawan lainnya dengan hak dan kewajiban yang sama. Mereka dilengkapi dengan surat tugas (kartu pers) saat melaksanakan tugasnya; (2) Wartawan Pembantu yaitu wartawan yang bekerja di satu perusahaan pers (cetak atau elektronik), tetapi tidak diangkat sebagai karyawan tetap. Mereka diberi honorarium yang disepakati, diberi surat tugas (kartu pers) serta bisa diberi tugas sesuai kemampuannya, dan 
dapat mewakili penerbitannya bila meliput satu peristiwa. Biasanya wartawan pembantu ini merupakan jenjang kedua sebelum diangkat menjadi wartawan tetap. (3) Wartawan Lepas (freelance), yaitu wartawan yang tidak terikat pada satu perusahaan media massa baik cetak maupun elektronik. Mereka bebas mengirimkan beritanya ke berbagai media massa. Jika berita atau tulisannya itu dimuat, mereka mendapatkan honorarium, tetapi jika tidak dimuat, tidak mendapat imbalan apa-apa (Djuroto, 2000:22).

Meski sudah disebutkan ada wartawan pembantu, menurut Djuroto koresponden (stringer) diartikan sama dengan wartawan pembantu, yaitu seseorang yang berdomisili di suatu daerah -bisa berasal dari daerah itu sendiri atau orang lain yang ditugaskan di daerah tersebut, diangkat atau ditunjuk oleh suatu penerbitan pers di luar daerah atau luar negeri, untuk menjalankan tugas kewartawanannya, yaitu memberikan laporan secara kontinyu tentang kejadian atau peristiwa yang terjadi di daerahnya. Tugas dan wewenang koresponden ini sama dengan wartawan tetap di suatu perusahaan penerbitan pers. la mendapatkan fasilitas yang sama dan berhak mewakili penerbitannya dalam kegiatan-kegiatan kewartawanan. Sistem pengiriman beritanya dilakukan dengan surat menyurat (korespondensi). Itu sebabnya wartawan yang bertugas di daerah tersebut mendapatkan sebutan koresponden.

\subsection{Era Masyarakat Informasi Menstimulus Perkembangan Citizen Journalism}

Menurut pendapat Everet M. Rogers (dalam Abrar, 2003:17), mengatakan bahwa ada empat era komunikasi yang mengikuti peradaban masyarakat dunia yaitu: era komunikasi tulisan (4000 SM - sekarang); era komunikasi cetak (1456 - 60 sekarang); era telekomunikasi (1844 - sekarang); dan era komunikasi interaktif (1946 - sekarang). Era komunikasi interaktif inilah yang kiranya semakin terasa belakangan ini. Kegiatan jurnalisme yang semula hasilnya hanya dapat dinikmati pada waktu dan keadaan tertentu, sekarang tidak lagi. Semua orang, kapanpun dan dimanapun dapat dengan mudah menikmati hasil dari kegiatan jurnalisme ini. Hal ini terlihat dari ruang - durasi dan space - yang diberikan oleh media kepada khalayaknya untuk menyampaikan informasi apa yang ia punya dan disebarkan lewat media. Meskipun jurnalisme warga secara istilah memang baru dikenal baru-baru ini, akan tetapi secara konsep praktik jurnalisme warga ini sudah ada sejak manusia mengenal tulisan dan mengenal media sebagai saluran komunikasi massa.

Perkembangan jurnalisme warga ini dapat dipetakan kedalam dua tahapan yaitu: 1) jurnalisme warga yang berkembang pada media konvensional (media lama) baik itu media cetak maupun media penyiaran seperti radio dan televisi; 2) jurnalisme warga yang berkembang seiring dengan perkembangan media baru (Lindawati, 2012:119). Pada tahapan kedua inilah penulis menilai bahwa jurnalisme warga mengalami perubahan yang sangat kompleks dalam perkembangan media baru - dalam hal ini internet - yang mempermudah siapa saja untuk menjadi bagian darinya. 
Dalam citizen journalism, antara produsen dan konsumen berita tidak bisa lagi diidentifikasi secara rigid karena setiap orang dapat memerankan keduanya (Gillmor, 2004:12). Audience tidak hanya memerankan konsumen pasif yang hanya menerima berita, namun sekaligus dapat memproduksi beritanya sendiri. Dengan demikian posisi antara jurnalis sebagai pencari dan penulis berita, narasumber sebagai sumber berita dan audience sebagai konsumen berita sudah lebur.

Menurut J.D. Lasica (dalam Suwandi, 2010:30) mengkategorikan media citizen journalism ke dalam beberapa tipe: 1) Pemberdayaan masyarakat. Masyarakat dilibatkan dalam pembentukan atau penyebaran berita melalui piranti yang mereka miliki. Contoh: komentar user yang di-attach pada kisah-kisah berita, blog-blog pribadi, foto, atau video footage yang diambil dari handycam pribadi, atau berita lokal yang ditulis oleh anggota komunitas; 2) Situs web berita atau informasi independen seperti Consumer Reports, Drudge Report; 3) Situs berita partisipatoris murni seperti OhmyNews.com; 4) Situs media kolaboratif seperti Slashdot. com, Kuro5hin.com; 5) Bentuk lain dari media 'tipis' seperti mailing list, newsletter e-mail; dan 6) Situs penyiaran pribadi seperti situs penyiaran video, seperti KenRadio, YouTube.

Menurut Nurudin (2009:74), sejumlah kelebihan yang dimiliki jurnalisme warga ialah: 1) Memupuk budaya tulis dan baca masyarakat. Selama ini budaya kalah dengan budaya dengar dan lihat. Budaya tulis dan baca adalah budaya yang lebih mencerdaskan. Masyarakat bisa menulis apa saja dalam blog; 2) Mematangkan terciptanya public sphere (ruang publik) di masyarakat. Masyarakat bisa berdiskusi bebas dalam sebuah blog tanpa ada aturan, larangan tertentu seperti halnya yang dilakukan pada media utama; dan 3) Citizen journalism juga manifestasi fungsi watch dog (kontrol sosial) media. Ketika kekuasaan tidak bisa terkontrol secara efektif, blog memberikan suntikan vitamin untuk melakukan kontrol atas ketimpangan di masyarakat.

\subsection{Peran Kontributor dan Citizen Journalism Secara Industrial}

Aliansi Jurnalisme Independen (AJ) mencatat bahwa sebagian besar koresponden hanya mendapatkan upah dari berita yang dimuat. Mereka hanya menggantungkan pendapatan dari berita seharga Rp 9.500 - 60.000 (online), Rp 50.000-Rp 350.000 per berita (cetak), Rp $12.500-60.000$ per berita (radio), dan Rp 50.000 sampai 250.000 per berita (TV). Ini berarti dalam satu bulan rata-rata penghasilan mereka dari karya jurnalistik antara $\mathrm{Rp} 1.000 .000$ - Rp 1.500.000. upah yang jauh dari katagori layak untuk jurnalis, terutama yang sudah berkeluarga (Siaran Pers AJI Indonesia tahun 2012).

AJI menyebut upah jurnalis saat ini menyedihkan dan tidak sesuai besaran upah layak yang seharusnya diterima jurnalis pemula 2016. Padahal sesuai hasil penelitian lembaganya, besaran upah layak bagi jurnalis pemula 2016 seharusnya Rp 7.540.000. Upah layak itu meningkat disbanding tahun 2015 yaitu sebesar Rp 6.510.400. Deritanya, penghasilan layak di 
atas baru dapat diterima seorang jurnalis setelah bekerja lebih dari lima tahun. Banyak media laari dari tanggung jawabnya dengan memberikan berbagai istilah yang mengaburkan untuk jurnalis, mulai koresponden, kontributor, dan stringer. Padahal ketiga istilah itu tidak dikenal dalam UU Ketenagakerjaan.

Di Makassar ada seorang kontributor bekerja di perusahaan radio hanya menerima gaji sekitar Rp 500 ribu per bulan. Padahal secara teratur menyetor berita 2-3 berita per hari. Sedangkan di Jabodetabek, seorang konttributor harus bekerja ganda di dua perusahaan media online demi mengejar penghasilan lebih baik. Dari dua media online tersebut dia bisa memperoleh penghasilan Rp 3 juta per bulan. Dari salah satu media online yang berbasis di Jakarta, kontributor tersebut hanya memeroleh penghasilan Rp 1 juta per bulan. Jika dihitung nominal rupiah setiap berita, maka per berita dihargai sekitar $\mathrm{Rp} 10-100$ ribu untuk media online. Sedangkan media elektronik dapat menghargai berita yang diperoleh kontributor sebesar Rp 100 - 200 per berita. (https://purrwokertokita.com/peristiwa/menyedihkan-gajikontributor-daerah-ternyata-sangat-rendah.html).

Kontributor (stringer) yang lebih dikenal dengan sebutan dengan wartawan pembantu adalah seorang yang berdomisili di suatu daerah, diangkat atau ditunjuk oleh suatu media massa di luar daerah atau luar negeri untuk menjalankan tugas kewartawananya, yaitu memberikan laporan secara kontinyu tentang kejadian atau peristiwa yang terjadi di daerahnya. Tugas wewenang kontributor sama dengan wartawan tetap di suatu perusahaan media massa, kontributor daerah dapat menghadiri kegiatan-kegiatan kewartawanan mewakili media yang mengangkatnya. Sehingga perusahaan bisa lebih efisisen dari pada mengutus wartawannya lebih mudah mengangkat orang untuk menjadi kontributor dari daerah itu sendiri.

Seorang kontributor bisa berasal dari daerah itu sendiri atau orang lain yang ditugaskan di daerah itu. Kontributor atau penyumbang naskah/tulisan secara struktural tidak tercantum dalam struktur organisasi redaksi. la terlibat di bagian redaksi secara fungsional. Termasuk kontributor adalah para penulis artikel, kolomnis, dan karikaturis. Para sastrawan juga menjadi kontributor ketika mereka mengirimkan karya sastranya (puisi, cerpen, esai) ke sebuah media massa. Wartawan Lepas (Freelance Journalist) juga termasuk kontributor. Wartawan lepas adalah wartawan yang tidak terikat pada media massa tertentu, sehingga bebas mengirimkan berita untuk dimuat di media mana saja, dan menerima honorarium atas tulisannya yang dimuat. Termasuk kontributor adalah Wartawan Pembantu (Stringer). la bekerja untuk sebuah perusahaan pers, namun tidak menjadi karyawan tetap di perusahaan tersebut. la menerima honorarium atas tulisan yang dikirim atau dimuat.

Dalam penelitiannya yang berjudul Peran Kontributor Daerah dalam Pemberitaan di TVRI Riau-Kepri, dijelaskan bahwa dalam memperoleh berita yang masih berada di sekitar daerah Kota Pekanbaru, TVRI Riau masih menggunakan wartawan-wartawan yang bekerja di TVRI Riau-Kepri, sedangkan untuk daerah-daerah tertentu di luar Kota Pekanbaru TVRI Riau- 
Kepri sudah menggunakan kontributor daearah. Jumlah kontributor di perusahaan media massa berbeda-beda, ada yang memiliki kontributor di setiap daerah tetapi juga ada juga yang hanya memiliki di beberapa daerah saja. Biasanya penempatan kontributor berdasarkan potensi informasi atau berita yang dapat diperoleh dari daerah itu. Peran kontributor dalam pemberitaan di TVRI Riau-Kepri sudah dilaksanakan seluruhnya. Pada dasarnya kontributor daerah telah mampu mendapatkan berita di daerah untuk disiarkan di TVRI Riau-Kepri. Namun, akibat kurangnya sumber daya manusia yang berkompeten di bidang pemberitaan membuat hasil berita yang didapatkan kurang maksimal. Di samping itu, berita juga tidak bisa didapatkan secara keseluruhan karena kurangnya peralatan dan akses perjalanan menuju lokasi liputan berita. Hal ini membuat seluruh kinerja kontributor daerah tidak maksimal (Riza, 2015:65).

Dari temuan di atas, maka kemunculan citizen journalism tentu menjawab permasalahan yang ada yaitu jurnalisme warga dapat menggantikan jurnalis atau kontributor yang berkompeten di bidang pemberitaan. Apalagi hampir setiap orang telah memiliki camera recorder (camcorder) atau minimal smartphone yang memiliki fitur perekam gambar dan suara. Selain itu, sulitnya menuju lokasi peliputan dapat diakomodir oleh warga yang berada di dekat lokasi tersebut.

Semakin banyaknya perusahaan media yang mempekerjakan jurnalis berstatus kontributor membuat jaminan hidup bagi mereka tidak jelas. Perusahaan media kerap memanfaatkan ketidakjelasan status ini, untuk mengingkari hak-hak pekerja yang diatur dalam undang-undang ketenagakerjaan, enggan memberikan upah yang layak, enggan memberikan jaminan kesehatan serta tunjangan lainnya yang bisa membuat jurnalis kontributor bekerja lebih profesional.

Di sisi lain, honor citizen journalism di Indonesia justru cukup menggiurkan. Misalnya stasiun televisi Net TV melalui program Net CJ memberikan honorarium untuk kategori bukan berita eksklusif dengan area peliputan di Indonesia baik hardnews maupun news feature yang tayang akan mendapat honor Rp 250 ribu. Video berita untuk kategori bukan berita eksklusif dengan area peliputan di wilayah Asia akan mendapat honor Rp 500 ribu. Kategori bukan berita eksklusif dengan area peliputan di wilayah Eropa dan Amerika, Afrika, Kore Selatan, Jepang dan Arab Saudi nantinya diganjar bonus Rp 1 juta. Sedangkan berita eksklusif dengan area peliputan di wilayah manapun, akan dibayar serendah-rendahnya Rp 1 juta hingga Rp 5 juta. Ini angka yang sangat fantastis dibandingkan honor jurnalis biasa. Apalagi citizen journalist tidak berkewajiban untuk menyetorkan berita setiap harinya.

Citizen Journalism menjadi penting karena bisa menjadi pelengkap bagi “lubang-lubang” berita yang tidak terendus oleh para wartawan profesional. Kendati para citizen journalist tidak mendapatkan honor atau gaji atau royalty bahkan "kartu tanda pengenal anggota", mereka adalah kekuatan raksasa yang bisa dibangunkan demi mencapai kehidupan berdemokrasi yang lebih egaliter (http://m.kompasiana.com/supadiyanto/eranya-pewarta-rakyat-citizen- 
journalism-mapping-bisnis-media-mas-s-a-depan-2013_5500981a33311bb745117c1).

\section{Simpulan}

Semakin banyaknya perusahaan media yang mempekerjakan jurnalis berstatus kontributor membuat jaminan hidup bagi mereka tidak jelas. Disisi lain, media massa telah memberdayakan masyarakat dalam membuat informasi dan sekaligus menjadikan mereka sebagai produsen berita. Semakin terlihat jelas persaingan antara wartawan profesional dengan masyarakat pembuat berita (citizen journalism) dalam kedudukannya sebagai insan media. Perusahaan media massa mulai memberikan segala kebutuhan citizen journalism dan menarik perhatian mereka seperti dengan memberikan kompensasi berupa honorarium agar menjalankan kegiatan sebagai citizen journalism sesuai dengan aturan yang perusahaan tetapkan dan tentu menguntungkan bagi mereka. Sebagai masyarakat seharusnya juga mampu merasakan dan memaknai setiap kenyamanan yang diberikan oleh pihak media yang menaungi mereka, sehingga tidak terlena dan mampu mengambil sikap ketika menyadari bahwa mereka telah dimanfaatkan demi kepentingan sekelompok orang.

Sebagai saran, sebaiknya perusahaan media massa berperan aktif menjadi gatekeeper dalam setiap pemberitaan yang mereka berikan kepada khalayak agar media massa dapat memberikan berita-berita yang berkualitas. Media massa juga selalu tetap menjalankan tujuannya, yang utama adalah memberikan informasi (to inform), disusul tujuan memengaruhi (to persuade), dan menghibur (to entertain). Selain itu, perusahaan media massa sebaiknya dapat memberikan kesejahteraan yang baik bagi wartawannya agar timbul sense of belonging terhadap perusahaan, serta meningkatkan keterampilan jurnalistik para karyawannya agar mereka menjalankan profesionalismenya sebagai wartawan. Seorang jurnalis juga harus memiliki mental yang kuat agar sikap profesionalismenya tetap terjaga, karena banyak pihakpihak yang berkepentingan ingin memberdayakan mereka. Tak lupa, saran juga penulis tujukan kepada khalayak yang ingin atau yang tidak berpartisipasi dalam citizen journalism sebaiknya mempunyai literasi terhadap media massa agar menjadi cerdas dan kritis menyikapi setiap informasi yang diterima.

\section{Daftar Pustaka}

\section{Buku:}

Abrar, Ana Nadhya. 2003. Teknologi Komunikasi: Perspektif Ilmu Komunikasi. Yogyakarta: LESFI Bowman, Shane \& Willis, Chris. 2003. We Media: How Audience are Shaping the Future of News and Information. The Media Center at the American Press Institute Djuroto, Totok. 2000. Manajemen Penerbitan Pers, Bandung: PT. Remaja Rosdakarya. Nasution, Zulkarimen. Materi Pokok Perkembangan Teknologi Komunikasi. Jakarta: Universitas Terbuka 
Kurnia, septiawan Santana. 2005. Jurnalisme Kontemporer. Jakarta: Yayasan Obor Indonesia Kriyantono, Rachmat. 2006. Teknik Praktis Riset Komunikasi. Jakarta: Kencana. Nurudin. 2009. Pengantar Komunikasi Massa. Jakarta: PT Raja Grafindo Persada Suwandi, Imam. 2010. Langkah Otomatis Menjadi Citizen Journalism. Jakarta: Dian Rakyat

\section{Jurnal:}

Gillmor, Dan. 2005, Winter. Where Citizens and Journalists Intersect. Nieman Report, Vol 59. No 4, Halaman 11-13

Kurniawan, Moch. Nunung. 2007. Jurnalisme Warga di Indonesia, Prospek dan Tantangannya. Makara, Sosial Humaniora, Vol. 11 No. 2 Desember 2007 halaman 71-78

Lindawati dan Salamah, Irma. 2012. Pemanfaatan Informasi dan Teknologi Informasi Pengaruhnya Terhadap Kinerja Individual Karyawan. Jurnal Akuntansi dan Keuangan Vol. 14 No. 1 Mei 2012 halaman 56-58

\section{Web:}

Supadiyanto. 2013. Eranya Pewarta Rakyat (Citizen Journalism): Mapping Bisnis Media Mas(s) a Depan. http://m.kompasiana.com/supadiyanto/eranya-pewarta-rakyat-citizenjournalism-mapping-bisnis-media-mas-s-a-depan 2013_5500981a33311bb745117c1 (diakses 10 April 2018)

Dedi Yondra. 2016. Net CJ Tantang Warga Jadi Jurnalis Dapat Honorloh. http://www.jawapos. com/read/2016/02/25/19252/net-cj-tantang-warga-jadi-jurnalis-dapat-honor-loh (diakses 10 April 2018)

Suhanudin, http://entertainment.suaramerdeka.com/index/php/id=720 (diakses 6 April 2018)

Purwokerto Kita. 2015. Peristiwa Menyedihkan Gaji Kontributor Daerah Ternyata Sangat Rendah. https://purwokertokita.com/peristiwa/menyedihkan-gaji-kontributor-daerahternyata-sangat-rendah.html (diakses 10 April 2018)

Nagari Novianto. 2016. Upah Jurnalis Kontributpr Bisa Bikin Anda Menangis. http:// siagaindonesia.com/122965/upah-jurnalis-kontributor-bisa-bikin-anda-menangis.html (diakses 10 April 2018)

Zaini Achmad. 2012. http://m.kompasiana.com/orangradio/buramnya-nasib-jurnalis-kontribu tor_55106795a33311c839ba801c (diakses 10 April 2018)

\section{Skripsi:}

Moslem Ahmad Hestu Riza. 2015. Peran Kontributor Daerah dalam Pemberitaan di TVRI Riau Kepri. Skripsi. Universitas Islam Negeri Sultan Syarif Kasim Pekanbaru-Riau 